\title{
Perception and development of Theory of Mind Reasoning in Asurini children, from Amazonia, Brazil ${ }^{1}$
}

\author{
ALINE BEGKMANN DE CASTRO MENEZES, MARILU MICHELLY DA SILVA GRUZ, \\ HELLEN VIVIANNI VELOSO CORREA*, REGINA BRITO
}

\begin{abstract}
Theory of Mind (ToM) approaches the ability to understand the possibility that even if one individual thinks something, another individual may think it differently. ToM is essential to socialization and it is developed around the age of 5 years. Most studies on the subject were made with children from industrialized societies instead of being made with children from traditional ethnic societies. This study aims to provide ToM developmental data from a sample of indigenous ethnicity - Asurini ethnicity. A sample of 35 children aged 2-10 years took part in this research. They were individually presented to a standard false-content task. The results did not indicate that 5 years is a marker of ToM in all children, this ability was manifested in children with age of 3 $(25 \%)$ to 9 years $(67 \%)$, and in all participants aged 10 . This variation could be related to typical environmental and ecological arrangements of the ethnicity.
\end{abstract}

Palavras-chave: Theory of Mind; traditional ethnic societies; false-belief tasks.

A Teoria da Mente (TdM) aborda a capacidade de entender a possibilidade de que mesmo se um indivíduo pensa alguma coisa, outro indivíduo pode pensar diferentemente. O desenvolvimento da TdM é essencial para a socialização, o que se inicia em torno dos 5 anos. A maior parte dos estudos sobre o tema foi realizada com crianças de sociedades industrializadas ao invés crianças de sociedades étnicas tradicionais. O presente estudo teve por objetivo fornecer dados referentes ao desenvolvimento da TdM em uma etnia indígena brasileira - a Asurini. Trinta e cinco crianças com idades entre 2 e 10 anos participaram de uma tarefa de falsa crença. Os resultados não indicaram que 5 anos é um marcador da TdM em todas as crianças, habilidade que se manifestou em crianças entre $3(25 \%)$ a 9 anos (67\%) e em todos os participantes de 10 anos. Essa variação pode estar relacionada à organização ambiental e ecológica específicas.

Keywords: Teoria da Mente; sociedades étnicas tradicionais; testes de falsa crença.

\section{Introduction}

Theory of Mind (ToM) has been defined by Oberle (2009) as "an everyday understanding of the mind" (p. 39) referring to the ability to develop beliefs regarding other's thoughts and their behaviors. Oberle (2009) adds that "all of our everyday actions and interactions are based on the kinds of beliefs, thoughts, desires and intentions people ascribe to each other" (p. 40). For several authors (Barret et. al, 2014; Oberle, 2009), the understanding of "other peoples' beliefs, desires and intentions and predicting their actions based on this knowledge" (Oberle,
2009, p. 39) is important to develop ToM because this ability improves social skills (e.g, through cooperation and communication) or increases chances of success in direct or indirect competition.

It has been studied as a developmental marker, since it requires the cognitive ability to understand that other people may have different beliefs than one's may own because of different interactions with the environment. Currently there is no consensus on the age children display ToM, which seems to depend on the use of elicited-response or spontaneous-response tasks (Barret et al., 2014). Accordingly to Barret et al. (2014), the difference

\footnotetext{
1 This study is an independent research of the Laboratory of Advanced Studies in Evolutionary Psychology/Grupo de Estudos Avançados em Psicologia Evolucionista - GEAPE. This article had the financial and operational support of the educational institution, University of Pará, Ipiranga Foundation (as an initiative to strengthen indigenous research in Amazonia- Brazil) and by the International Society for Human Ethology (ISHE) through a research project approved by this institution.

* Post-Graduate Program in Theory and Behavior Research - Universidade Federal do Pará, Rua Augusto Corrêa, 01 - Campus Universitário do Guamá, CEP: 66.075.110, Belém (PA), Brasil. vivianniveloso@yahoo.com.br. tel/fax: (91) 3344-0700.
} 
in findings is due to differences in the skills required by each method.

In spontaneous-response false-belief tasks the researcher measures the spontaneous reaction of children to false-beliefs situations by the direction of their gaze, for example (Barrett et al., 2014). Through this type of task researchers have found results indicating that this ability appears even earlier: in the firsts two years of life (Barrett et al., 2014; He, Bolz \& Baillargeon, 2011; Miller, 2009; Perner \& Roessler, 2012; RubioFernández \& Geurts, 2012). Cross-cultural work with spontaneous tests in traditional and non-industrialized societies of China, Ecuador and Fiji have been conducted by Barrett et al. (2014), results have shown the existence of ToM in children up to 2 years old.

Accordingly to Oberle (2009), elicited-response in false-belief tasks are usually performed in one of three different forms: change-in-location task, change-in-content task and surprise-content task. Those are variations of situations in which the researcher makes the child a direct question about the most likely behavior of an individual who has a false belief. In all three forms of tasks, the development of $\mathrm{ToM}$ is assumed if the child answer differentiating his/her own knowledge from others'. This type of research usually finds results indicating that children display this ability around 3-5 years of age (Miller, 2009; Rubio-Fernández \& Geurts, 2012).

Even when considering only elicited-response tasks, it is important to observe the development of ToM by $4-5$ year old children reflects mostly researches made in Western cultures or in industrial societies with large cultural similarities to Western cultures (Miller, 2009; Oberle, 2009; Rubio-Fernández \& Geurts, 2012).

Oberle (2009) made a cross-cultural revision about the development of ToM and an experiment in Micronesian children through surprise-content task, an elicited-response test. The author found that in the ten different societies analyzed, evidence of the development of ToM was found in a range from 3 to 10 years old, presenting more evidence around the ages of 4 and 5. Oberle (2009) also discusses that in some societies age is related to access to formal education (when the access is bigger, the development of ToM happens sooner).

By questioning which variables would affect the performance in false-belief tasks, Milligan, Astington and Dack (2007) concluded "there is a significant relation between children's language ability and their falsebelief understanding that is not connected with age" (p. 635). According to these authors "age is not really an explanatory variable, but rather it is a proxy for various maturational factors that may explain variation, an important one of which is language ability" (p. 638). Many researchers point out the role of social interactions for the development of $\mathrm{ToM}$, especially verbal interactions with people from different ages (Lillard \& Kavanaugh, 2014; McAlister \& Peterson, 2013; Pavarini, Souza \& Hawk, 2013; Wang \& Su, 2009).

Considering that other variables may influence ToM establishment and the universal importance of this ability, it is important to increase the number of cross-cultural comparisons to investigate this issue. This study proposes to investigate the development of ToM in children of an indigenous Amazon society (ethnicity Asurini). Since the original culture (described below) persists in the Asurini village, it might have been expected that the results in elicited-response, surprisecontent, and false-belief tests would be similar to those found in other non-urban societies (such as those presented by Vinden, 1996 and Oberle, 2009), which are similar to results found in Western societies - having the age of 5 as an important developmental mark for ToM development. We aim to verify this hypothesis.

\section{Method}

\section{Participants}

All Asurini children between 2 and 10 years of age were considered able to participate, thus no sampling was made. From the total of 50 children only 35 took part in this research (18 girls, 17 boys). The others could not participate because they were involved in village tasks (see Table 1). This amount of children corresponds to $70 \%$ of the total of children in that age range in the village.

Table 1. Number of children in the village and in the research according to age.

\begin{tabular}{ccc}
\hline Age & $\begin{array}{c}\text { Number of children } \\
\text { in the village }\end{array}$ & $\begin{array}{c}\text { Number of } \\
\text { children in the } \\
\text { research }\end{array}$ \\
\hline 2 & 7 & 3 \\
3 & 9 & 6 \\
4 & 4 & 4 \\
5 & 8 & 7 \\
6 & 5 & 4 \\
7 & 5 & 3 \\
8 & 3 & 3 \\
9 & 6 & 3 \\
10 & 3 & 2 \\
Total & 50 & 35 \\
\hline
\end{tabular}


Ethnographic background

The Brazilian rural indigenous population is of $0.5 \%$ of the national population, representing more than 500 thousand people divided into 218 villages, according to a census made by the Education Ministry in 2002. One of those villages is the ethnic group of the Asurini with 141 people.

They are organized into one single village, where each house is settled around the taviva (where most of the rituals and festivals take place and the dead ones are buried) - at the right side of the Xingu River, in the State of Pará, Brazil, but they have moved to many different areas because of war and conflicts with opponent tribes. Although they have had rare and occasional contacts with white people since 1763 , the approximation was made by the Asurini, in 1971. Proud of their culture, they try to keep their cultural tradition, such as growing and hunting their food, valuing the relationship among relatives, dividing labor according to gender, educating children among adults with lots of freedom and implementing religious practices connected with the local nature (Domingues \& Domingues, 2008).

Their concept of childhood seems to be different from the one of industrialized communities, in which there is an excess of the children's innocence protection. In Asurini community children are exposed (with adult supervision) too early to essentials activities concerning the subsistence, such exposure is considered, by adults, as necessary for children to learn to deal with the absence of their elders. They think children need to learn so they should not be preserved from social nuances (Domingues \& Domingues, 2008). Oliveira (2014) points out that, in many indigenous societies children are given the autonomy to make their own decisions, without ignoring their apprentices condition.

Another characteristic of this group may also be important to understand ToM in the community is the fact that women have an average of 4 to 5 children. They consider themselves as adults between 11 and 12 years of age, moment they start getting married. This dynamic generates several consequences: 1) children live together with brothers and sisters of different ages (which also happens at school); 2) children need to look after younger siblings too early once daily tasks such as hunting and gathering require help from the older ones and; 3) they are exposed to great responsibilities since a very early age (Domingues \& Domingues, 2008).
Materials

As surprise content, we used a Brazilian

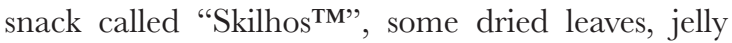
beans, some paper, pens, colored pencils and the Demographic and socio-demographic census of the population from the Assurini village.

\section{Environment}

Data collection was made in Asurini indigenous village situated by the Xingu river, in the State of Pará, Brazil.

To promote socialization with the children, a shed (building with a thatched roof, wooden fence, no walls, featuring a large table and two big benches) was used.

Two rooms of the local school were used to data collection since they allowed researchers to have privacy during data gathering.

\section{Ethical conduct}

The visit to the Asurini village had the approval from the official government institution Fundação Nacional do Índio (FUNAI) - through the Contract of Technical and Cientific Support between the Asurini Awaeté Association and the Ipiranga Foundation (of which the first author was an official member). Ipiranga Foundation is a nonprofit organization which aims to provide financial sustainability to Asurini people through the preservation of their culture.

\section{Procedure}

The procedure applied in this research is known as surprise-content task, a type of elicitedresponse false-belief task that was first developed by Hogrefe et al. (1986) and then consolidated by Gopnik and Astington (1988) as the "smartest task" (quoted by Oberle, 2009, p. 41).

Researchers performed socialization activities with the children since their first day in the village. These activities were always taken during the afternoon (between $14 \mathrm{~h}$ and $15 \mathrm{~h} 30 \mathrm{~min}$ ) and consisted in making drawings with the children in the shed of the association. At the third day, researchers gave a package of snacks ("Skilhos"TM) by the end of activity. This was done as a control measure to ensure all children had received the snack and would be able to recognize its package. The 
participation of children under 12 years old was allowed in this activity.

Data were collected on the fourth day with the assistance of one of the village's residents and of the school teacher, both previously instructed about the research. The kids were taken to school, staying in the "waiting room" to draw the activity proposed, where they were supervised by one of the researchers. The village's teacher had to lead the children from the "waiting room" to the research room, where interviews were being made.

Only the researcher and the resident remained inside the research room, being responsible for the question's translation from Portuguese to Asurini, when necessary.

By pointing out to the snack package, four questions were made by the researcher during the session. Inside the package there were dried leaves rather than the expected snack. At this point, leaves could not be seen by the participant. Based on Oberle's procedure (2009), the questions were:

1. "What do you think is inside the package?". The child was asked to answer the question, and then the package containing dried leaves was opened by the researcher. After showing the inside of the package to the child, question 2 was made;

2. "What is it inside the package? What do you see?" After answering, a third question was asked to the child;

3. "X didn't see what is inside the package. What do you think that $\mathrm{X}$ may think is inside of it?" (the one used as reference usually was a child who lived in the same village and was of the same age).

At the end, independently of their behavior, each one of them received jelly beans as a reward for participating. All questions were asked in Portuguese. In cases when the child seemed to be uncomfortable with the situation, the village's resident translated the questions to the Asurini language and children could also answer to it in the same language.

\section{Results}

Each child answered the first question correctly, recognizing the package as a snack package. The second question was also answered correctly by everyone. However, from 33 children, 8 of them refused to answer the third question. Results for these 25 children can be seen at Figure 1. The data of two of them (one was 2 years old and the other was 9 years old) were not analyzed because data gathering was affected by external influences. It was not possible to make statistical analysis because the number of children in the village (composed by 142 people) was very small.

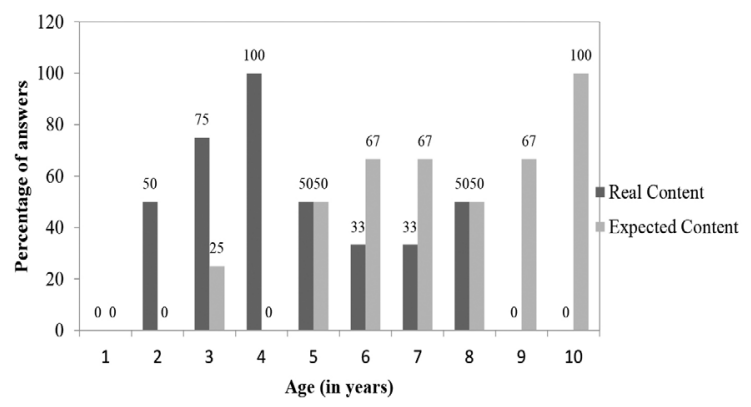

Figure 1. Percentage of answers to the question "X did not see what is inside the package. What do you think that $\mathrm{X}$ think is inside the package?" according to age.

Those children who answered the package content correctly failed the false-belief task and could not display ToM. Those who answered the expected content - before seeing the dried leaves - succeeded in the task and can be assumed to have ToM. From the results presented in Figure 2, it can be observed that ToM appears in children at only 3 years of age, but the rate of success in the task is far smaller than the failure one. By 5 years of age, this scenario starts to change, presenting increases in success and decreases in failure rates. Therefore, it is possible to say that ToM's development timeline starts in children of 3 years, increases among 5 -year-olds, finally achieving $100 \%$ in children of 9 years old (Figure 2).

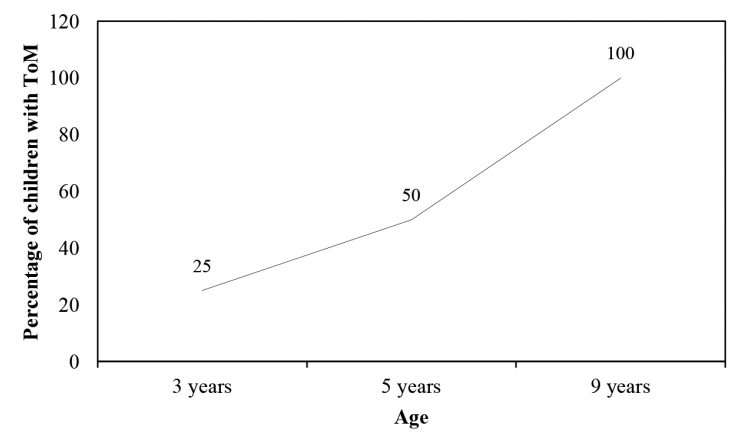

Figure 2. Percentage of children displaying ToM at 3, 5 and 9 years of age. 


\section{Discussion}

Oberle (2009) argues in her article on the difficulty to accept ToM as an universal pattern, intrinsic to each society, because of the restrict number of researches involving non-western children or from small eastern societies. This article aims to contribute to this area by producing new data related to the investigation of ToM in a Brazilian indigenous village. The findings provide interesting discussions and some reflections regarding ToM's universality.

This study proposed to verify the hypothesis that results in elicited-response, surprise-content, and in false-belief tests would be similar to those found in other non-urban societies, having the age of 5 as an important mark for ToM's development. Although it was found out that the age of 5 is a mark in developmental timeline, the development of ToM varied between 3 and 9 years, thus the hypothesis was only partially confirmed. This section will present some possible interpretations of the results.

It may be said that there is no specific age for the universal development of ToM, only a propitious period to its presence (by the age of 5). Variations on age may result from different needs and environmental contingencies that children are exposed to. For example, although Oberle (2009) found indications of false-belief understanding around 5 years of age in western societies, the same article presents a research with non-western cultures of Peru that reports children of 8 years old without ToM evidence. According to Wang and $\mathrm{Su}$ (2009), the period of acquisition of ToM, even when different cultures and educational levels are considered, would be between 3 and 7 years of age.

In the present study, evidence of ToM was found, through false-content tasks, in every child of 9-10 years. The same ability was already seen in some 3 -year-old children (25\%), in a large number in 5 -year-old children $(50 \%)$ and in most children from 6 years of age $(67 \%)$. This result diverges from the data described by Miller (2009) "3-year-old children typically fail the false-belief task, 4-year-old children show a bit of success and 5-year-old children typically succeed" (p. 749). Despite of taking 4 years longer for evidence to be found in all children, the present study found positive results earlier than Miller's study (2009): being of 9 years in this study and of 5 years in Miller's study (2009). Comparing the present data to the revision presented by Oberle (2009), the results obtained here are similar to those found by Vinden (1996) in Quechuaspeaking children from Peru and by Vinden (2002, quoted by Oberle, 2009) in Mofu children from Cameroon. In this last society, it was found that $45 \%$ of the 5-year-old, non-educated children presented false-belief understanding.

Experiments as those of Callaghan et al. (2005) and Mayer and Träuble (2012) false-belief task, specifically through change-in-location tasks, in children from Samoa, showed results in which there was a great tendency towards achieving success belatedly. In the first study, not every 5-year-old children succeeded the test (13 children between 18), which is no longer expected for this age. While children in the second study only obtained complete success at age of 8 years, with significant levels compared to other ages. Mayer and Träuble (2012) wanted to replicate the study made by Callaghan et al. (2005), changing some details to improve the procedure, and even so, the results for children from Samoa indicated a delay in the development or appearance of ToM.

Some scientists consider that it was in the period comprehended between 3 and 7 years of age that the transition between not having into having ToM occurred (Wang \& Su, 2009), while other researchers have hypothesized this transition occurs well before 3 years (Barret et al., 2014). The main difference in results is that, among Asurini children, the range of individual development is broader. This range can be seen in data of some 3-year-old children who already presented ToM, while some 8-year-old children lacked this ability yet. This interpersonal variability is an important evidence to question which elements may influence the development of ToM.

Social and individual variations, such as children-of-different-age interactions (siblings or not) and interaction with their parents (Lillard \& Kavanaugh, 2014; McAlister \& Peterson, 2013; Pavarini, Souza \& Hawk, 2013; Wang \& Su, 2009), also can develop ToM earlier or complicate its performance. These interactions possibly have characteristics that help children think about their world and consequently about people.

A key feature of these interactions is the verbal interaction on a large scale, and other activities that include it, such as playing make-believe, competitions among siblings (usually with the older ones) or colleagues, listening to parents advising other siblings (Lillard \& Kavanaugh, 2014; Wang \& Su, 2009; McAlister \& Peterson, 2013), conversations at home about emotional states and desires, maternal references to mental states, referrals from parents about the causal relationship between behavior and mental states as well as the confrontation between 
the mental states of the child and of the colleague (Pavarini, Souza \& Hawk, 2013).

ToM is presented by Oberle (2009) as a great advantage to the human because it enables humans to have the capacity to understand other people, their beliefs, desires and intentions, making social interactions easier. However, the early development of ToM may not be necessary in a society where beliefs are shared by all and desires and intentions are not private (because of a less complex culture, lesser life options or even because the environment arrangement does not allow to hide actions).

In the Asurini village, children live with each other in an environment that belongs to them all. The toys these children are used to play are actual parts of the environment such as the river, fruits, animals, and branches of trees. Houses do not have doors to close and the concept of privacy is diffused. Moreover, no emphasis to individual performance is given to the activities developed in the group. It also appears in their verbal behavior: it lacks discussions on feelings and emotions, being mainly focused in event descriptions (Castro Menezes, 2008; Domingues \& Domingues, 2008). Therefore, it is hard to separate what belongs to an individual as a different thing from what belongs to the rest of the inhabitants of the village in this context. It is as hard as pointless. In this scenario, the need for differentiation from others may occur later than in western industrialized cultures. In industrialized societies, the notion of ownership and individuality is developed sooner through the distinction between which one is "my toy" and which one belongs to others. Looking inside the school's environment, this reality is more evident since western educational system embraces competition, demands the understanding among its students, thus it is possible to be better, and teachers pressure to understand feelings and thoughts.

That discussion might explain the delay in acquiring ToM observed in some of the children. Then, it is possible to question: why there are any Asurini children of 3 years of age who have already presented ToM? A study of Wang and Su (2009) shows interaction with children at different ages may stimulate the comprehension of false-beliefs, especially when older children teach the younger ones. This type of interaction described by Wang and $\mathrm{Su}(2009)$ is very common on a daily basis among Asurini children, who begin to look after younger siblings and cousins around the age of 3 years. It may be assumed that the cultural context of the village enables the development of ToM, but does not make it an early requirement for social interactions, resulting in a broad range of ages for ToM to appear.

Lane et al. (2013) propose that temper, particularly aggression or social withdrawal, may be factors that facilitate the delayed appearance of ToM. It was also found the excess of coercive parental punishment seems also to influence the understanding of false-belief in a negative way (Pavarini, Souza \& Hawk, 2013). Considering the Asurini's culture is described as a facilitating type of social exposure, with reduced use of aggression in general and coercitive parental punishments (see Castro Menezes, 2008 and Domingues \& Domingues, 2008), these factors may contribute to the creation of a propitious environment for the development of ToM.

Although an influence of culture upon the moment and the process of ToM development is observed, it is important to emphasize that in different cultures, the developmental stage in which ToM occurs is the same. Despite some minor differences, this study corroborates the hypothesis that ToM development around the age of 5 years is universal and can happen earlier with 3-years-olds. This universality may be understood by the findings of Liu et al. (2009) and Sabbagh et al. (2009) that present neural correlates to the performance on "false-belief" tasks. They sustain ToM needs some specific neural development to be achieved and that these neural correlates are consolidated among ages 3-5. Before that ToM is not expressed because children do not have this ability.

This study is limited. It was not possible to apply the procedure to every child in the village, thus, the number of participants is small, making the use of valid statistic testing impossible. It was also not possible to use the "educational level" as a variable, since some of the children go to school (almost $40 \%$ of them). Their educational model is not comparable to most traditional schools of Brazilian cities. At last, the refuse of 8 children on answering the last question may reflect the strangeness of the experimental situation, especially because being asked about thoughts is not part of their regular interactions. Maybe the procedure could be better adjusted to enhance the participation.

Barrett et al. (2014) are followers of the spontaneous method and point out the main drawback of the elicited method is placed on the demand for executive functions (Rubio-Fernández \& Geurts, 2012) not acquired by children before age 4 . In other words, they already have ToM, but they are not able to express it, which is also a limitation of the present 
study. Considering that elicited-response tasks demand verbal behavior and that this kind of behavior is not so stimulated in the Asurini community, it may be an important variable to some participants, affecting their result.

The results presented here might be compared with those obtained by Mayer and Träuble (2012) with the Samoa, where there was an apparent delay in the emergence of ToM. That study was conducted in an area of Samoa (not controlled by the United States), where the collective life is similar to indigenous villages of Amazon (Domingues \& Domingues, 2008). There is a central area in this region where people gather to do their daily activities, cook, eat, and work, like an extension of their home; such a structure is likely to provide a good socialization among group members.

According to Mayer and Träuble (2012), it is common for children to sleep in the house of their relatives rather than their parents, as if all houses belonged to everyone. In these circumstances, it is likely that children coexist with people (especially children) of various ages since early; a variable that increases the probability of early success in false-belief tasks (Lillard \& Kavanaugh, 2014 tests, Wang \& Su, 2009; McAlister \& Peterson, 2013). Even when considering this interaction with children and adults of various ages, Wellman et al. (2006) suspect that adults apparently express little interest in the mental state of other individuals and maybe do not give emphasis to these states when interacting with children, factor also considered very important for ToM to appear (Pavarini, Souza \& Hawk, 2013). However, Mayer and Träuble (2012) avoid stating the main factor for this apparent delay is the lack of mental states emphasis, and suggest further research.

Even though many similarities may be observed between these two societies, results were different; ToM emerged later in Samoa than in Asurini. These differences indicate there are possibly variables that should be better investigated. In the present study, authors point out information on participant's number of siblings, sequence of birth and the type of interaction between parents and children could have been crucial to verify individual differences among these groups.

It is possible to say the concept of childhood among the Asurini people enables different experiences from those from non-indigenous groups and may possibly help in a sooner acquisition of ToM. The ideal is for these more detailed comparisons to be made in non-industrialized communities, which will help to understand why ToM is expressed more or less belatedly.

Nevertheless, this study provides important contributions to the understanding of the Theory of Mind, using the false-content task in a society that has never been investigated before. Moreover, the participation of older children enabled the observation of the development of this ability in a representative number of children of this community, registering the absence of the ability until it was present in all children participating.

Other studies should be made in Asurini children in the future, regarding the cognitive development and the formation of "self". Those studies will collaborate even more to the understanding of the effects of the cultural reality of the Asurini upon children development as a whole.

\section{Acknowlegments}

This research was partially funded by the International Society of Human Ethology, through the Owen F. Aldis Fund Scholarship Award given to Manuela Beltrão, and by the Ipiranga Foundation, enabling the trip necessary to visit the Asurini village with financial and legal resources.

\section{References}

Barret, H. C., Broesch, T., Scott, R. M., He, Z., Baillargeon, R., Wu, D., Bolz, M., Henrich, J., Setoh, P., Wang, J., \& Laurence, S. (2014). Early false-belief understanding in traditional non-Western societies. Proceedings of the Royal Society B, 28, 1-7. http://dx.doi. org/10.1098/rspb.2012.2654.

Callaghan, T., Rochat, P., Lillard, A., Claux, M. L., Odden, H., Itakura, S., Tapanya, S., \& Singh, S. (2005). Synchrony in the onset of mental - state reasoning. Psychological Science, 16, 378-384. doi: 10.1111/j.14679280.2006.01830.x.

Castro Menezes, S. M. (2008). Cultura e identidade do povo Asurini: a mulher na transmissão dos saberes e fazeres culturais. (Master's thesis). Universidade Estadual de Taubaté, São Paulo.

Domingues, V. C. de L., \& Domingues, W. C. L. (2008). A cultura estuprada? "Aí o pessoal ficou com vergonha de ser índio e começou a querer estudar." Infância, 
educação e escola entre os Asurini do Xingu. (Bachelor's thesis). Graduação em Pedagogia, campus Altamira, Universidade Federal do Pará.

Gopnik, A., \& Astington, J. W. (1988). Children's understanding of representational change and its relation to the understanding of false belief and the appearancereality distinction. Child Development, 59, 26-39.

He, Z., Bolz, M., \& Baillargeon, R. (2011). False-belief understanding in 2.5-years-olds: Evidence from violation-of-expectation change-of-location and unexpected-contents tasks. Developmental Science, 14 (2), 292-305. doi: 10.1111/j.1467-7687.2010.00980.x.

Hogrefe, G. J., Wimmer, H., \& Perner, J. (1986). Ignorance versus false belief: A developmental lag in attribution of epistemic states. Child Development, 57, 567-582.

Lane, J. D., Wellman, H. M., Olson, S. L., Miller, A. L., Wang, L., \& Tardif, T. (2013). Relations between temperament and theory of mind development in the United States and China: biological and behavioral correlates of preschoolers' false-belief understanding. Developmental Psychology, 49(5), 825-836. doi: 10.1037/ a0028825.

Lillard, A. S., \& Kavanaugh, R. D. (2014). The contribution of symbolic skills to the development of an explicit theory of mind. Child Development, 00, 1-17. doi: $10.1111 /$ cdev. 12227 .

Liu, D., Sabbagh, M. A., Gehring, W. J., \& Wellman, H. M. (2009). Neural correlates of children's theory of mind development. Child Development, 8(2), 318-326.

Mayer, A., \& Träuble, B. E. (2012). Synchrony in the onset of mental state understanding across cultures? A study among children in Samoa. International Fournal of Behavioral Development, 37, 21-28. doi: 10.1177/0165025412454030.

McAlister, A. R., \& Peterson, C. C. (2013). Siblings, theory of mind, and executive functioning in children aged 3-6 years: new longitudinal evidence. Child Development, 84(4), 1442-1458. doi: 10.1111/cdev.12043.

Miller, S. A. (2009). Children's understanding of secondorder mental states. Psychological Bulletin, 135(5), 749773.
Milligan, K., Astington, J. W., \& Dack, L. A. (2007). Language and theory of mind: meta-analysis of the relation between language ability and false-belief understanding. Child Development, 78(2), 622-646.

Oberle, E. (2009). The development of theory of mind reasoning in Micronesian children. Fournal of Cognition and Culture, 9, 39-56.

Oliveira, A. C. (2014). Indígenas crianças, crianças indígenas: Perspectivas para construção da doutrina da proteção plural. Curitiba, PR: Juruá.

Pavarini, G., Souza, D. H., \& Hawk, C. K. (2013). Parental practices and Theory of Mind Development. Fournal of Child and Family Studies, 22, 844-853. doi: 10.1007/ s10826-012-9643-8.

Perner, J., \& Roessler, J. (2012). From infant's to children's appreciation of belief. Trends in Cognitive Sciences, 16(10), 519-525.

Rubio-Fernández, P., \& Geurts, B. (2012). How to pass the false-belief task before your fourth birthday? Association for Psychological Science, 24, 27-33. doi: 10.1177/0956797612447819.

Sabbagh, M. A., Bowman, L. C., Evraire, L. E., \& Ito, J. M. B. (2009). Neurodevelopmental correlates of theory of mind in preschool children. Child Development, 80(4), 1147-1162.

Vinden, P. G. (1996). Junín Quechua children's understanding of mind. Child Development, 67, 1707-1716.

Vinden, P. G. (2002). Understanding minds and evidence for belief: a study of mofu children in Cameroon. International Fournal of Behavioral Development, 26, 445-452. doi: 10.1080/01650250143000391.

Wang, Y., \& Su, Y. (2009). False belief understanding: Children catch it from classmates of different ages. International Fournal of Behavioral Development, 33 (4), 331-336.

Wellman, H. M., Fang, F., Liu, D., Zhu, L., \& Liu, G. (2006). Scaling of Theory-of-Mind Understandings in Chinese Children. Psychological Science, 17, 1075-1081. doi:10.1111/j.1467-9280.2006.01830.x. 